\title{
An analysis of anxiety and selected aspects of personality in women with ischemic heart disease according to P.T. Costa and R. R. McCrae theory - The role of psychosocial factors in ischemic heart disease
}

\author{
Alicja Nasiłowska-Barud ${ }^{1,2, A-F \oplus}$, Tomasz Zapolskii, ${ }^{2, A, C-F}{ }^{\oplus}$, Małgorzata Barud ${ }^{3, B-C \oplus}$, \\ Andrzej Wysokiński' ${ }^{2, A, F}$ \\ ${ }^{1}$ Department of Clinical Psychology, Medical University, Lublin, Poland \\ ${ }^{2}$ Department of Cardiology, Medical University, Lublin, Poland \\ ${ }^{3}$ Department of Anaesthesiology and Intensive Therapy, Medical University, Lublin, Poland \\ A - Research concept and design, B - Collection and/or assembly of data, C - Data analysis and interpretation, \\ $D$ - Writing the article, E-Critical revision of the article, F - Final approval of article
}

\begin{abstract}
Nasiłowska-Barud A, Zapolski T, Barud M, Wysokiński A. An analysis of anxiety and selected aspects of personality in women with ischemic heart disease according to P.T. Costa and R. R. McCrae theory - The role of psychosocial factors in ischemic heart disease. Ann Agric Environ Med. 2021; 28(1): 107-113. doi: 10.26444/aaem/118430
\end{abstract}

\begin{abstract}
Introduction. Risk factors for ischemic heart disease (IHD) are very numerous and not fully defined. In addition to classic risk factors, different factors are also distinguished, among them psychological aspects chich have rarely been subject to detailed analyses.

Objective. The aim of study was an analysis of the anxiety structure, including the five factors of personality: neuroticism (NEU), extraversion (EXT), openness (OPE), agreeableness (AGR) and conscientiousness (CON), in women with IHD.

Materials and method. The study involved 140 women aged 37-74 years with IHD confirmed by coronary angiography. Psychological examination was conducted using R.B. Cattell's IPAT Anxiety Scale and P.T. Costa and R.R. McCrae's NEO-FFI Personality Inventory.

Results. The results obtained from the IPAT Anxiety Scale showed that the study group of 140 women with IHD had the correct level of internal integrity $\left(\mathrm{Q}_{3}^{-}\right)$. The dominant factor in the anxiety structure in $88.7 \%$ of subjects was neurotic tension $\left(\mathrm{Q}_{4}^{+}\right)$. A lack of sense of safety was indicated by $72.6 \%$ of subjects $\left(\mathrm{L}^{+}\right), 69.3 \%$ experienced a strong tendency to self-blame and experience a sense of guilt $\left(\mathrm{O}^{+}\right)$, and over $51.6 \%$ of women with IHD expressed decreased emotional stability $\left(\mathrm{C}^{-}\right)$. The level of general anxiety was high ( $G A=7.3)$. The analysis of the five factors of personality revealed that the dominant factors in the structure of personality of women with IHD were CON in 69.3\%, AGR in $46.7 \%$ and EXT in $45.2 \%$. NEU and OPE were moderately significant factors.

Conclusions. Women with IHD are characterised by a high level of anxiety, increased neurotic tension, decreased emotional stability, auto-aggression and a sense of danger and distrust. Women with IHD demonstrate a high level of factors, such as extraversion, agreeableness and conscientiousness.
\end{abstract}

Key words

personality, anxiety, women, ischemic heart disease

\section{INTRODUCTION}

Ischemic heart disease (IHD) is currently the most frequent cause of death in both men and women in developed countries. The main risk factors for circulatory system diseases, such as hypercholesterolemia, diabetes, arterial hypertension, smoking, obesity, personality, stress, gender, hereditary factors, etc., were attributed only to men until the 1980s; however, in the last 20 years they have also become highly significant for women [1]. According to a report by the American Heart Association, heart diseases in women have been described as a 'silent epidemic' [2].

An increase in morbidity and mortality caused by

Address for correspondence: Tomasz Zapolski, Department of Cardiology, Medical University Lublin, Poland

E-mail: zapolia@wp.pl

Received: 20.10.2019; accepted: 25.02.2020; first published: 20.03.2020 circulatory system diseases in women is related, among others, to the quick development of our civilisation $[3,4]$. Women have undergone a lifestyle change and adopted male lifestyle patterns, as well as male professional and social roles. They work long hours, often in difficult conditions, and occupy responsible positions in companies. Cigarette smoking has become more and more widespread among women, as well as using other stimulants, eating irregularly, getting little sleep and insufficient rest $[5,6]$. Nowadays, women live incredibly fast-paced lives, under the pressure of time, and overburdened with abundant tasks. They strive to achieve more and more and, at the same time, they feel that they are unsuccessful in some areas. Such a lifestyle leads to the occurrence of circulatory system diseases, including IHD, before the menopausal period $[7,8]$.

Cardiovascular risk factors can be divided into three groups: behavioural, somatic and psychosocial. Some of 
the behavioural and somatic cardiovascular risk factors are closely related to psychosocial factors. Tobacco smoking is a behavioural risk factor that seems to be of particular importance and has two negative consequences. From a pathophysiological point of view, this addiction is the primary and well-known risk factor for atherosclerosis. In turn, from the psychological aspect, depression, anxiety as a trait, and anxiety as a state, are more severe in subjects with nicotine dependence than in healthy individuals [9]. Atherosclerosis belongs to the most common complications of diabetes mellitus, which is also a somatic factor of cardiovascular risk. A significant association between depression and diabetic complications has been identified [10]. The prevalence of anxiety and depression among type 2 diabetes mellitus patients was statistically significantly higher in females than in males [10]. This clinical evidence linking behavioural and somatic factors with psychological factors is also reflected in the data from basic research. Studies conducted by Shi have shown that there is a relationship between depression and endothelial dysfunction in the general population [11].

There is also a specific psychological aspect in women with IHD. It should be stressed that among the factors predisposing women to IHD are psychological factors, such as anxiety, depression, constant sense of danger, subdued aggression and anger, neurotic tension, excessive ambition, penchant for extreme order, rigour and strict planning of all tasks, as well as living under the pressure of time $[12,13]$.

Symptoms of depressed mood and depression occur in women twice as frequently as in men. Women show lower resistance to stressful situations and experience the feeling of anxiety much more frequently than men [14]. Anxiety is one of the most frequent and the most intensive emotional responses to pain connected with heart muscle ischemia. In studies of patients with myocardial infarction, increased anxiety levels were observed in over two-thirds of these patients. In one-quarter, it was as high as in people with mental disorders [15]. A study conducted by Cerano et al. involving a population of patients after myocardial infarction showed that anxiety disorders occur more frequently in women than in men [16].

Many years of observations and clinical experience have confirmed that anxiety disorders are notably involved in the etiopathogenesis of ischemic heart disease. Cardiac muscle diseases, especially in their acute phase, intensify anxiety disorders. However, insufficient studies have been conducted so far to confirm and evaluate this possible correlation [17, 18]. The performance of directed studies on the involvement of anxiety and personality traits in the etiopathogenesis of ischemic heart disease, as well as the treatment and rehabilitation of IHD patients, may clarify selected problems connected with the mental functioning of patients with ischemic heart disease. Therefore, any scientific approach to this problem may prove significant.

\section{OBJECTIVE}

The aim of the study was to describe the structure of anxiety and analysis of the five personality factors: neuroticism, extraversion, openness, agreeableness and conscientiousness, described in the five factor model by P. T. Costa and R. R. McCrae in women with ischemic heart disease (IHD).

\section{MATERIALS AND METHOD}

The study involved women hospitalised in the Department of Cardiology who underwent coronary angiography in order to evaluate the condition of the coronary vessels. In all women, IHD was confirmed angiographically, manifesting as significant stenosis in one or more coronary arteries.

Women who were qualified for the study had been treated for at least three months. Reasons for exclusion from the study were the occurrence of an acute coronary event or the presence of other diseases within the three months prior to commencement of the study. One hundred and forty women aged $37-74$ years, mean age 56.6 years, were included in the study. All patients expressed consent for psychological examination which constituted a part of the complex treatment process.

Before conducting the questionnaire survey, a detailed psychological history was taken from each patient, including questions concerning somatic ailments, neurotic disorders, mood, family, professional and material situation, as well as treatment possibilities.

The level and structure of anxiety were examined using the R. B. Cattell IPAT Anxiety Scale, in authorised translation by Z. Płużek and K. Hirszel, and the NEO-FFI Personality Inventory by P. T. Costa and R. R. McCrae. The psychological questionnaires used were adapted to Polish conditions. The American version of R. B. Cattell's IPAT Anxiety Scale consists of 40 questions, while the Polish version includes 20 additional experimental questions. The questionnaire is used for evaluation of the intensity and structure of anxiety by using five factors:

1) personal integrity $\left(Q_{3}^{-}\right)$;

2) emotional stability $\left(\mathrm{C}^{-}\right)$;

3) vigilance $\left(\mathrm{L}^{+}\right)$;

4) apprehension $\left(\mathrm{O}^{+}\right)$;

5) neurotic tension $\left(\mathrm{Q}_{4}^{+}\right)$.

The characteristic feature of anxiety as understood by Cattell is the tendency for long-term association with the personality traits and its explanation as a possible delayed reaction to past conflicts and stress [19]. R. B. Cattell's IPAT Anxiety Scale enables evaluation of the level of general anxiety (GA), as well as explicit (AE) and implicit anxiety (AI).

The NEO-FFI Personality Inventory by P. T. Costa and R. R. McCrae consists of 60 questions and allows for the evaluation of five aspects of personality:

- neuroticism (NEU);

- extraversion (EXT);

- openness (OPE);

- agreeableness (AGR);

- conscientiousness (CON).

This is the five factor model, the so-called 'Big Five' [20]. The severity of anxiety and personality traits is expressed using a standard 10-psychometric scale which contains 10 units. A unit on psychological scale is a sten (abbrev. for 'standard 10') [21].

Bioethics. Approval for the study was obtained from the Bioethics Committee of the University of Lublin (KE0254/2015). Informed consent was obtained from each patient, and the study protocol conformed to the ethical guidelines of the 1975 Declaration of Helsinki. 
Statistical analysis. The results obtained from the $\mathrm{R}$. B. Cattell IPAT Anxiety Scale and P. T. Costa and R. R. McCrae NEO-FFI Personality Inventory were statistically analysed and psychologically interpreted. The psychological interpretation was conducted using a 10-grade scale and presented in graphical form. Statistical analysis was carried out on an IBM PC using a standard statistical package (SPSS for Windows Version 12.0; SPSS INC, Chicago, Il., USA). The results were tested for normality. Data were expressed as mean $\pm \mathrm{SD}$ (parametrically distributed continuous variables) and percentage (categorical variables). The relationship between two continuous variables was calculated using linear correlation and the Pearson correlation coefficient. Probability values of $<0.05$ were accepted as significant.

\section{RESULTS}

There were $29 \%$ of women with university education, $52 \%$ with secondary education, $14 \%$ with vocational education, and $5 \%$ with primary education.

Angiographic evaluation of coronary vessels revealed narrowing within one coronary vessel in 56 patients (40\%), two coronary vessels in $36(25.7 \%)$ and three vessels in 22 patients (15.7\%). In 26 (18.6\%) women, there were small mural lesions in coronary vessels.

Analysis of the results obtained, based on the IPAT Anxiety Scale by R. B. Cattell are presented in Table 1 and in the information provided about the structure and intensity of unease and anxiety in women with IHD. Table 1 also shows study results obtained on the basis of the NEO-FFI Personality Inventory by P. T. Costa and R. R. McCrae.

Table 1. IPAT Anxiety Scale by R. B. Cattell and Personality Inventory by P. T. Costa and R. R. McCrae. Mean values and standard deviations in women with IHD $(\mathrm{N}=140)$

\begin{tabular}{|c|c|c|}
\hline $\begin{array}{l}\text { R. B. Cattell - IPAT Anxiety Scale } \\
\text { Anxiety Factors }\end{array}$ & $\mathbf{x}$ & SD \\
\hline Personal integrity - $\mathrm{Q}_{3}^{-}$ & 4,85 & 1,96 \\
\hline Emotional stability - $\mathrm{C}^{-}$ & 6,20 & 2,11 \\
\hline Vigilance - $\mathrm{L}^{+}$ & 6,36 & 2,12 \\
\hline Apprehension - $\mathrm{O}^{+}$ & 7,82 & 1,96 \\
\hline Neurotic tension - $\mathrm{Q}_{4}^{+}$ & 9,22 & 1,20 \\
\hline General anxiety - GA & 7,25 & 1,62 \\
\hline Anxiety implicid - Al & 16,98 & 5,17 \\
\hline Anxiety explicid - AE & 19,37 & 7,04 \\
\hline \multicolumn{3}{|l|}{$\begin{array}{l}\text { P. T. Costa and R. R. McCrae } \\
\text { Personality Inventory Factors }\end{array}$} \\
\hline Neuroticism - NEU & 5,45 & 2,40 \\
\hline Ekstraversion - EXT & 5,98 & 2,05 \\
\hline Openness to Experience - OPE & 4,20 & 2,52 \\
\hline Agreeableness - AGR & 6,86 & 1,91 \\
\hline Conscientiousness - CON & 6,90 & 2,06 \\
\hline
\end{tabular}

The results of the examination conducted using the R. B. Cattell IPAT Anxiety Scale show that the study group of 140 women with IHD demonstrated the correct level of internal integrity or personal integrity $\left(\mathrm{Q}_{3}^{-}\right)$. Almost half of the studied women with IHD (48.5\%) did not have any problems with a lack of personal integrity and did not experience crises of values. $51.6 \%$ of subjects showed a tendency towards decreased emotional stability $\left(\mathrm{C}^{-}\right)$, and $72.6 \%$ experienced a strong sense of insecurity, i.e. a lack of sense of personal security $\left(\mathrm{L}^{+}\right)$. The high $\mathrm{O}^{+}$score in $69.3 \%$ of patients showed that women with IHD had a strong tendency towards selfblame and sense of guilt. The dominant factor in the structure of anxiety, observed in $88.7 \%$ of women with IHD, was neurotic tension $\left(\mathrm{Q}_{4}^{+}\right)$(Fig. 1 and Tab. 2).

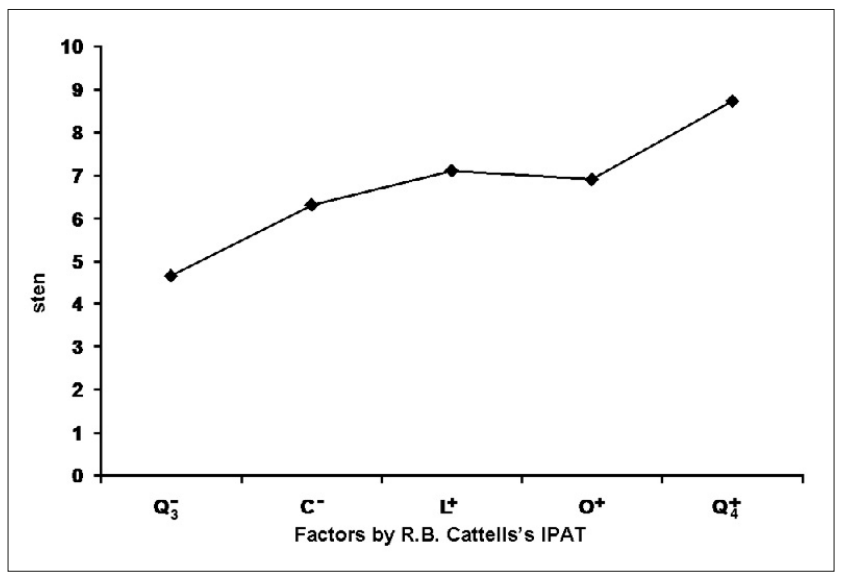

Figure 1. R. B. Cattell IPAT Anxiety Scale. Mean profile of women with ischemic heart disease (IHD) $\mathrm{N}=140$.

$\left(\mathrm{Q}_{3}^{-}\right.$- personal integrity; $\mathrm{C}^{-}$- emotional stability, $\mathrm{L}^{+}$- vigilance, $\mathrm{O}^{+}$- apprehension and $\mathrm{Q}_{4}^{+}$- neurotic tension)

Table 2. Distribution of low (1-4), middle (5-6) and high (7-10) results of examination conducted using R. B. Cattell - IPAT Anxiety Scale, and P. T. Costa and R. R. McCrae NEO-FFI Personality Inventory in a group of women with ischemic heart disease $(\mathrm{N}=140)$

\begin{tabular}{|c|c|c|c|}
\hline \multirow[b]{2}{*}{$\begin{array}{l}\text { R.B. Cattell The IPAT Anxiety Scale } \\
\text { Anxiety Factors }\end{array}$} & \multicolumn{3}{|c|}{ Percentage distribution of the results } \\
\hline & $\begin{array}{c}\text { low } \\
1-4(\%)\end{array}$ & $\begin{array}{l}\text { middle } \\
5-6(\%)\end{array}$ & $\begin{array}{c}\text { high } \\
7-10(\%)\end{array}$ \\
\hline Personal integrity $-\mathrm{Q}_{3}^{-}$ & 48.38 & 29.04 & 22.58 \\
\hline Emotional stability - $\mathrm{C}^{-}$ & 22.58 & 25.81 & 51.61 \\
\hline Vigilance $-\mathrm{L}^{+}$ & 1.61 & 25.81 & 72.58 \\
\hline Apprehension $-\mathrm{O}^{+}$ & 8.06 & 22.59 & 69.35 \\
\hline Neurotic tension $-\mathrm{Q}_{4}^{+}$ & 1.61 & 9.69 & 88.70 \\
\hline General Anxiety - GA & 3.22 & 33.88 & 62.90 \\
\hline $\begin{array}{l}\text { P. T. Costa and R. R. McCrae } \\
\text { Personality Inventory Factors }\end{array}$ & $\begin{array}{c}\text { low } \\
1-4(\%)\end{array}$ & $\begin{array}{l}\text { middle } \\
5-6(\%)\end{array}$ & $\begin{array}{c}\text { high } \\
7-10(\%)\end{array}$ \\
\hline Neuroticism - NEU & 32.25 & 41.95 & 25.80 \\
\hline Extraversion - EXT & 19.35 & 35.49 & 45.16 \\
\hline Openness to experience - OPE & 33.88 & 38.71 & 27.41 \\
\hline Agreeableness - AGR & 8.06 & 45.17 & 46.77 \\
\hline Conscientiousness - CON & 19.35 & 11.30 & 69.35 \\
\hline
\end{tabular}

Women with IHD had moderate values of neuroticism (NEU) and openness (OPE). However, in over $25.8 \%$ of patients, the level of neuroticism was high, and $27.4 \%$ had a high level of openness. The dominant and above average factors in over $45 \%$ of subjects were extraversion (EXT), agreeableness (AGR), and in almost $70 \%$ conscientiousness (CON). Such a combination of factors allowed the women with IHD to be described as people who try to stay calm and maintain emotional balance, but who experience feelings of sadness and a sense of guilt (NEU). Their activity is directed towards the environment, expressing openness and a friendly attitude; they look for stimulation in their social contacts; 
they try to be hospitable, sociable and active (EXT); appreciate traditional values and prefer socially acceptable ways of behaviour. Their interests are pragmatic (Tab. 2 and Fig. 2).

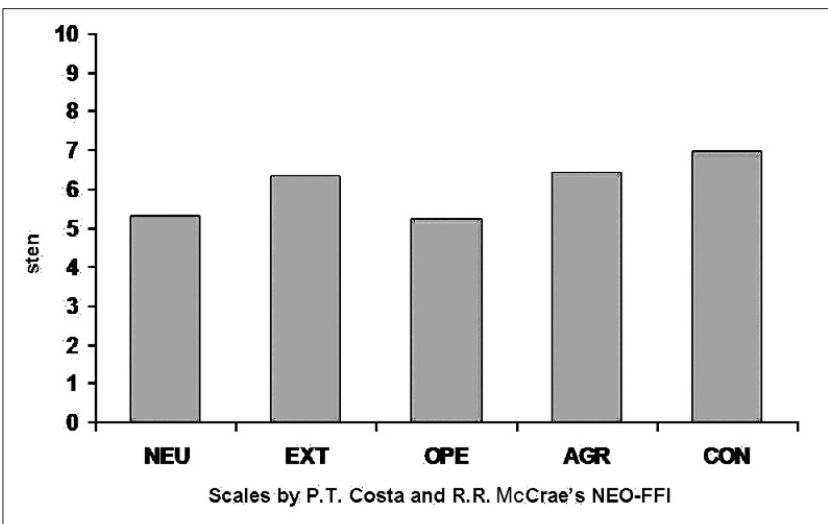

Figure 2. P. T. Costa and R. R. McCrae NEO-FFI Personality Inventory. Mean profile of women with ischemic heart disease (IHD) N $=140$.

NEU - neuroticism; EXT - extraversion; OPE - openness; AGR - agreeableness; CON - conscientiousness.

The above average score linked to the agreeableness factor (AGR) demonstrated that the study subjects were ready to help others. They tried to be straightforward, sincere, modest and sensitive in relation to other people. They were characterised by a high level of conscientiousness and strong will, as well as a tendency to keep things in order and strive for perfectionism. Such a collection of traits motivated the patients to dutifulness and resilient and meticulous activities (CON).

The analysis of correlations demonstrated statistically significant correlations between a moderate level of neuroticism (NEU) and:

- personal integrity $\mathrm{Q}_{3}^{-}(\mathrm{r}=0.36 ; \mathrm{p} \leq 0.004)$;

- emotional stability $\mathrm{C}^{-}(\mathrm{r}=0.30 ; \mathrm{p} \leq 0.01)$;

- tendency to self-blame $\mathrm{O}^{+}(\mathrm{r}=0.36 ; \mathrm{p} \leq 0.0004)$;

- neurotic tension $\mathrm{Q}_{4}^{+}(\mathrm{r}=0.31 ; \mathrm{p} \leq 0.01)$;

- implicit anxiety AI $(\mathrm{r}=0.29 ; \mathrm{p} \leq 0.01)$; explicit anxiety AE $(\mathrm{r}=0.58 ; \mathrm{p} \leq 0.0001)$;

- general level of anxiety GA ( $r=0.50 ; \mathrm{p} \leq 0.0001)$.

These results enabled the conclusion to be drawn that in women with IHD, the more integrated the personality, the lower the level of neurotic traits. With the intensification of neurotic traits, the level of emotional stability decreased, and there was an increase in the tendency to self-blame and sense of guilt, as well as higher internal tension. With the intensification of neurotic symptoms, the level of hidden anxiety and apparent anxiety, as well as general anxiety, also increased (Tab. 2).

There was a negative correlation between openness (OPE) and poor personal integrity $\mathrm{Q}_{3}^{-}(\mathrm{r}=-0.27 ; \mathrm{p} \leq 0.03)$, autoaggression $\mathrm{O}^{+}(\mathrm{r}=-0.27 ; \mathrm{p} \leq 0.03)$, and apparent explicit anxiety AE $(\mathrm{r}=-0.27 ; \mathrm{p} \leq 0.03)$. The results showed that the level of openness decreased with the deterioration of internal personal integrity. With a decreased level of openness (OPE), there was a higher tendency to self-blame $\mathrm{O}^{+}(\mathrm{r}=-0.27 ; \mathrm{p} \leq 0.03)$ and intensified symptoms of apparent explicit anxiety AE $(r=-0.27 ; p \leq 0.03)$. Similarly, the level of agreeableness (AGR) decreased with the decline of personal integrity $\mathrm{Q}_{3}^{-}(\mathrm{r}=-0.28$; $\mathrm{p} \leq 0.02)$, while the symptoms of hidden anxiety implicit
Table 3. Analysis of correlation (Pearson's r correlation) between results obtained using P. T. Costa and R. R. McCrae NEO-FFI Personality Inventory and R. B. Cattell IPAT Anxiety Scale on a group of women with ischemic heart disease $(\mathrm{N}=140)$

\begin{tabular}{|c|c|c|c|c|c|c|}
\hline \multirow{2}{*}{$\begin{array}{l}\text { R. B. Cattell } \\
\text { The IPAT Anxiety } \\
\text { Scale } \\
\text { AnxietyFactors }\end{array}$} & \multicolumn{6}{|c|}{$\begin{array}{l}\text { P. T. Costa and R. R. McCrae NEO-FFI Personality Inventory } \\
\text { Factors }\end{array}$} \\
\hline & & $\begin{array}{c}\text { Neuro- } \\
\text { ticism } \\
\text { NEU }\end{array}$ & $\begin{array}{c}\text { Extra- } \\
\text { version } \\
\text { EXT }\end{array}$ & $\begin{array}{l}\text { Open- } \\
\text { ness } \\
\text { OPE }\end{array}$ & $\begin{array}{l}\text { Agree- } \\
\text { ableness } \\
\text { AGR }\end{array}$ & $\begin{array}{c}\text { Conscien- } \\
\text { tiousness } \\
\text { CON }\end{array}$ \\
\hline Personal integrity & $r$ & 0.36 & -0.42 & -0.27 & -0.28 & -0.27 \\
\hline$-Q_{3}^{-}$ & $\mathbf{p}$ & 0.004 & 0.7 & 0.03 & 0.02 & 0.000 \\
\hline Emotional & $r$ & 0.30 & -0.04 & 0.00 & -0.16 & -0.33 \\
\hline stability - C- & $p$ & 0.01 & 0.74 & 0.94 & 0.21 & 0.007 \\
\hline Vigilance & $r$ & 0.23 & 0.10 & -0.02 & -0.17 & 0.06 \\
\hline$-\mathrm{L}^{+}$ & $\mathrm{p}$ & 0.06 & 0.41 & 0.84 & 0.16 & 0.60 \\
\hline Apprehension & $r$ & 0.36 & 0.03 & -0.27 & 0.06 & -0.27 \\
\hline$-\mathrm{O}^{+}$ & $\mathbf{p}$ & 0.004 & 0.79 & 0.03 & 0.58 & 0.02 \\
\hline Neurotic tension & $r$ & 0.31 & -0.17 & -0.16 & -0.14 & -0.11 \\
\hline$-\mathrm{Q}_{4}^{+}$ & $\mathbf{p}$ & 0.01 & 0.18 & 0.20 & 0.25 & 0.35 \\
\hline Anxiety implicit & $r$ & 0.29 & 0.11 & -0.08 & -0.31 & -0.35 \\
\hline$-A \mathrm{I}$ & $\mathrm{p}$ & 0.01 & 0.36 & 0.50 & 0.01 & 0.004 \\
\hline Anxiety explicit & $r$ & 0.58 & -0.13 & -0.27 & -0.17 & -0.35 \\
\hline$-\mathrm{AE}$ & $\mathrm{p}$ & 0.000 & 0.29 & 0.03 & 0.17 & 0.005 \\
\hline General anxiety & $r$ & 0.50 & 0.05 & -0.18 & -0.30 & -0.33 \\
\hline$-G A$ & $\mathrm{p}$ & 0.000 & 0.66 & 0.15 & 0.017 & 0.008 \\
\hline
\end{tabular}

intensified AI ( $\mathrm{r}=-0.31 ; \mathrm{p} \leq 0.01)$. With the decrease in the level of conscientiousness CON ( $r=-0.27$; $\mathrm{p} \leq 0.02)$, there was an increased tendency to experience a sense of guilt and selfblame $\mathrm{O}^{+}$, as well as symptoms of hidden implicit anxiety AI $(\mathrm{r}=-0.35 ; \mathrm{p} \leq 0.004)$, apparent explicit anxiety $\mathrm{AE}(\mathrm{r}=-0.35$; $\mathrm{p} \leq 0.005)$, and general anxiety GA $(\mathrm{r}=-0.33 ; \mathrm{p} \leq 0.008)$.

\section{DISCUSSION}

Long-term psychological studies conducted among patients with cardiovascular diseases indicate that high levels of fear and anxiety are characteristic for men with IHD. A high level of fear plays an important role in the etiology and treatment of hypertension [22], cardiac arrhythmias [23], gastric and duodenal ulcer diseases [24], diabetes [25], metabolic diseases and cancer [26]. High levels of fear and anxiety are found in patients with heart defects qualified for cardiac surgery [27].

At the end of the 1970s, scientific research demonstrated deviations concerning epidemiology, diagnostics, course and prognosis of cardiac diseases in women, including ischemic heart disease. So-called 'feminine' risk factors were indicated. Such factors as smoking, oral contraception, insufficient physical activity and excessive body weight were considered to be especially significant [2]. It was also established that lack of support from family members and loneliness were significant risk factors for myocardial infarction and sudden cardiac death [1].

It was pointed out that depression had an important impact on the development and course of ischemic heart disease, both in men and women [28]. A large prospective HAPIEE study found significant positive associations between increasing depressive symptoms and cardiovascular mortality and, to a lesser extent, with all-cause mortality [29]. Studies conducted among young women with a history of heart infarction showed that they suffered from depression, and the intensification of depressive symptoms was much higher than 
in the case of men [30]. Several mechanisms are suggested to explain the link between depression and cardiovascular disease, including behavioural factors (e.g. smoking, insufficient physical activity or alcohol consumption) and direct effects corresponding with somatic risk factors (e.g. via increased platelet activity, inflammation) [31, 32].

So far, anxiety disorders among people with circulatory system diseases have not been as thoroughly analysed as depression. They are currently under investigation in many scientific centres, both in the United States and many European countries. Anxiety is the first and the most dominant emotional reaction to coronary complications. In this context, cardiac rehabilitation appears to be the right time to manage psychological disorders in heart disease patients in order to help them reduce the deleterious effects of stress, anxiety and depression on their minds and bodies [33].

International prospective studies conducted by Moser et al. among women from Australia, England, Japan, South Korea and the USA, showed that women with a history of myocardial infarction had a higher level of anxiety than men. The high level of anxiety in the studied women persisted despite social support and psychological help provided for them [34].

Twenty years of prospective observations of initially healthy women conducted by Eaker et al. in the course of the Framingham Study, confirmed the correlation between anxiety symptoms and myocardial infarction. A correlation was also found between anxiety attacks and sudden cardiac death. Thus, anxiety has been treated as an independent factor predisposing to ischemic heart disease [35].

In recent years, much attention has been paid to neurotic changes in ischemic heart disease. It was confirmed that these changes coexisted with clinical symptoms of IHD, but they were not always connected with the presence of coronary atherosclerosis [36]. Quite recently, using the example of a county in the USA, Eichstaedt et al. demonstrated a robust positive relationship between negative emotions expressed in twitter messages and cardiovascular deaths, thus strengthening the link between negative thinking and cardio-metabolic disorders [37].

The most well-known studies are those conducted in the 1990 s by Costa and Stone which involved patients with ischemic heart disease. The authors examined the structure of their personality using five factors - neuroticism, extraversion, openness, agreeableness and conscientiousness. Neuroticism is one of the five dimensions of personality, and some of its features, e.g. anger, subdued aggression, hostility, low or depressive mood, have been regarded as risk factors for IHD. Neuroticism increased the risk of cardiovascular disease [38]. The studies conducted among IHD patients demonstrated that stenocardial pain was accompanied by an increased level of neurotic changes. The authors of the study did not obtain an unequivocal answer to the question whether neuroticism might be regarded asan IHD risk factor, but the results showed that there was a very strong correlation between neuroticism and IHD [39, 40].

The results of the study involving 140 women with IHD presented in the current study allowed the confirmation of a high level of anxiety and the description of dominant traits in the structure of patients' anxiety. They also provided an opportunity for characterisation of traits dominating in the structure of personality of women with IHD analysed in relation to the so-called 'Big Five'. The study subjects revealed a high level of general anxiety with neurotic tendencies. In almost half of the patients, anxiety had an apparent form. The dominant factor in the anxiety structure was neurotic tension accompanied by an intensified internal conflict between the superego and the psychological drives sphere, auto-aggression syndrome and decreased emotional stability. Women with IHD showed low toleration for difficulties and stress, neurotic fatigue, and distrust with regard to the surroundings and insecurity. The patients revealed a high level of tension connected with the so-called state of frustration, that is the conflict between the requirements of the superego and the sphere of psychological drives. A high level of ambition and high sensitivity to any kind of failure were also characteristic for these patients.

According to the concept of R. B. Cattell, the anxiety experienced by women with ischemic heart disease should be classified as characterological anxiety. This is connected to experiences, internal conflicts and personal difficulties, and may be the result of a high level of ambition and high intellectual needs.

The women with IHD included in the study were characterised by a high level of conscientiousness and openness. They had strong will and motivation for action and realisation of their goals. The 5-Factor Model showed that extraversion, openness and mainly conscientiousness were protective dimensions in terms of health [41]. A recently published study using the 5-Factor Model showed that personality traits correlate with markers of inflammation [42]. Research performed by Mõtus et al. demonstrated that conscientiousness is associated with lower systemic inflammation, which may explain the lower frequency of metabolic syndrome and cardiovascular complications in this group of patients [43]. This can also explain better somatic outcomes stemming from protective or less dangerous behaviour. Conscientious patients, especially women, generally listen to health advice, present less risky behaviours (smoking, use of alcohol and unbalanced diet) and comply with medical treatment [33].

The women with IHD were submissive towards their surroundings and at the same dutiful, meticulous, punctual and reliable at work. They revealed a tendency towards undertaking too many tasks and feeling excessively responsible for them. They lived fas-t paced lives under the pressure of time. In a situation of real or hypothetical danger, such a set of features in women with IHD may predispose them to react with fear, even in the event of ordinary, everyday life difficulties.

The results of the study involving 140 women with IHD presented in the current study allowed for the characterisation of anxiety and such personality structure factors as: neuroticism, extraversion, openness, agreeableness and conscientiousness. At the same time, these results revealed new problems. It seems justifiable to analyse the correlation between the degree of disease progression (on the basis of the degree of narrowing and number of affected coronary vessels) and the personality profile. Thus, the study requires continuation with a larger group of patients with ischemic heart disease.

Limitations. The etiology of IHD is very complex. This applies especially to women, where, apart from the socalled classical risk factors, there are also a number of nonclassical cardiovascular risk factors [44]. In addition to the 
documented impact on the development of IHD, factors from both groups are also risk markers of psychological disorders in women. This applies to low physical activity, obesity and related diabetes, and dyslipidemias, as well as the importance of smoking, sleep disorders and menopause. At the same time, anxiety disorders and depression are known risk factors for IHD [28]. This may have an effect of a vicious circle because obesity, low physical activity, sleep disturbance or smoking, are risk factors for IHD [45]. On the other hand, these factors obviously adversely affect the psyche of ill women. [46]. They can therefore aggravate the importance of anxiety and personality traits in the development of IHD. Potentially, therefore, this may disproportionately increase the adverse impact of these atherosclerosis risk factors on IHD development than would result from their isolated direct impact $[11,28]$. These factors were not analyzed separately in the study. The aim of the study was not to analyze the relationship of IHD risk factors, but only the relationship of angiographically confirmed IHD with the structure of anxiety and personality traits. These IHD risk factors may, however, be subject to other dedicated analyses in subsequent studies using the R. B. Cattell IPAT Anxiety Scale and the P. T. Costa and the R. R. McCrae NEO-FFI Personality Inventory applied in the current study.

\section{CONCLUSIONS}

Women with IHD are characterised by a high level of anxiety, increased neurotic tension, decreased emotional stability, auto-aggression, and a sense of danger and distrust. Women with IHD demonstrate a high level of factors, such as extraversion, agreeableness and conscientiousness. Women with ischemic heart disease need appropriate forms of psychological help to decrease their levels of anxiety.

\section{Acknowledgement}

The study was supported by the Grant No. DS 377 from the Medical University in Lublin, Poland

\section{REFERENCES}

1. Lubiszewska B, Skóra E, Kruk M, Broda G, Księżycka E, Kurjata P, et al. Prevalence of classical risk factors in Polish women with premature coronary artery disease. Kardiol Pol. 2010; 68: 1032-7.

2. Benjamin EJ, Virani SS, Callaway CW, Chamberlain AM, Chang AR, Cheng S, et al. Heart Disease and Stroke Statistics-2018 Update A Report From the American Heart Association. Circulation. 2018; 137: e67-e492.

3. Kershaw KN, Brenes GA, Charles LE, Coday M, Daviglus ML, Denburg NL, Kroenke CH, Safford MM, Savla T, Tindle HA, Tinker LF, Van Horn L. Associations of stressful life events and social strain with incident cardiovascular disease in the Women's Health Initiative. J Am Heart Assoc. 2014; 3: e000687.

4. Felix AS, Lehman A, Nolan TS, Sealy-Jefferson S, Breathett K, Hood DB, Addison D, Anderson CM, Cené CW, Warren BJ, Jackson RD, Williams KP. Stress, resilience, and cardiovascular disease risk among black women. Circulation: Cardiovascular Quality and Outcomes. 2019;12: e005284

5. Colpani V, Baena CP, Jaspers L, van Dijk GM, Farajzadegan Z, Dhana K, Tielemans MJ, Voortman T, Freak-Poli R, Veloso GGV, Chowdhury R, Kavousi M, Muka T, Franco OH. Lifestyle factors, cardiovascular disease and all-cause mortality in middle-aged and elderly women: a systematic review and meta-analysis. Eur J Epidemiol. 2018; 33(9): 831-845.

6. Domíngu F, Fuster V, Fernández-Alvira, JM, Fernández-Friera L, López-Melgar B, Blanco-Rojo R, Fernández-Ortiz A, García-Pavía
P, Sanz J, Mendiguren J, Ibañez B, Bueno H, Lara-Pezzi E, Ordovás JM. Association of sleep duration and quality with subclinical atherosclerosis. J Am Coll Cardiol. 2019; 73(2): 134-144.

7. Nasiłowska-Barud A, Zapolski T, Barud M, Wysokiński A. Overt and covert anxiety as a toxic factor in ischemic heart disease in women: The link between psychological factors and heart disease. Med Sci Monit. 2017; 23: 751-8.

8. Mehta P K, Wei J, Wenger N K. Ischemic heart disease in women: A Focus on risk factors. Trends Cardiovasc Med. 2015; 25(2): 140-5.

9. Pietras T, Witusik A, Panek M, Szemraj J, Górski P. Anxiety, depression and methods of stress coping in patients with nicotine dependence syndrome. Med Sci Monit. 2011; 17: CR272-6.

10. Mikaliūkštienė A, Žagminas K, Juozulynas A, Narkauskaitė L, Sąlyga J, Jankauskiené K, et al. Prevalence and determinants of anxiety and depression symptoms in patients with type 2 diabetes in Lithuania. Med Sci Monit. 2014; 20: 182-90.

11. Shi H, Feng G, Wang Z, Zhou C, Zhong G, Hu Y, et al. Relationships between Depressive Symptoms and Endothelial Function Among Outpatients of a General Hospital in China. Med Sci Monit. 2015; 21: 1812-9.

12. Vaccarino V, Bremner JD. Behavioral, emotional and neurobiological determinants of coronary heart disease risk in women. Neurosci Biobehav Rev. 2017; 74: 297-309.

13. Carney RM, Freedland KE. Depression and coronary heart disease. Nat Rev Cardiol. 2017; 14: 145-155.

14. Fauerbach JA, Bush DE, Thombs BD, McCann UD, Fogel J, Ziegelstein RC. Depression following acute myocardial infarction: a prospective relationship with ongoing health and function. Psychosomatics. 2005; 46: $355-1$.

15. Lichtman IH, Froelicher ES, Blumenthal IA, Carney RM, Doering LV, Frasure-Smith N, et al. Depression as a risk factor for poor prognosis among patients with acute coronary syndrome: systematic review and recommendations: a scientific statement from the American Heart Association. Circulation. 2014; 129: 1350-1369.

16. Celano Ch, Daunis D, Lakko H, Campbell K, Huffman J. Anxiety disorders and cardiovascular disease. Curr Psychiatry Rep. 2016; 18(11): $101-110$.

17. Khayyam-Nekonei Z, Neshatdoost H, Yousefy A, Sadeghi M, Manshaee S. Psychologiacal factors and coronary heart disease. Atherosclerosis. 2013; 9: 102-111.

18. Sadowski M, Gąsior M, Gierlotka M, Janion M, Poloński L. Clinical characteristics of Polish women with ST-segment elevation acute myocardial infarction. Kardiol Pol. 2010; 68: 627-4.

19. Mack M, Gopal A. Epidemiology, traditional and novel risk factors in coronary artery disease. Heart Failure Clinics. 2016; 12(1): 1-10.

20. McCrae RR, Costa PT Jr. Validation of the five-factor model of personality across instruments and observers. J Pers Soc Psych. 1987; 52: 81-90.

21. Hornowska E. Testy psychologiczne: teoria i praktyka. Warszawa. Scholar; 2007: 136.

22. Nasiłowska-Barud A, Żuk M, Jabłońska-Brzozowska J, Wysokiński A, Brzozowski W. Psychological problems in patients with atrial fibrillation. Post Nauk Med. 2015; 8: 540-544.

23. Nasiłowska-Barud A, Kowalik M. Characteristics of depressive changes and anxiety in patients with essential hypertension. An UMCS Sec D. 2004; 59(1): 428-433.

24. Young Bok L, Jihan MD Y, Hyun Ho C, Bu Seok J, Hyung-Keun K, SangWoo K, Sung Soo K, Yong Gyu P, Hiun Suk C. The association between peptic ulcer diseases and mental health problems. A population-based study a STROBE compliant article. Meidcine. 2017; 96(34): e7728.

25. Robinson D, Coons M, Haensel H, Valais M, Yale J-F. Diabetes Canada 2018 clinical practice guidelines for the prevention and management of diabetes in Canada. Can J Diabetes. 2018; 42 (Suppl 1): S130-S141.

26. Unseld M, Krammer K, Lubowitzki S, Jachs M, Baumann L, Vyssoki B, Riedel J, Puhr H, Zehentgruber S, Prager G, Masel EK, Preusser M, Jaeger U, Gaiger A. Screening for post-traumatic stress disorders in 1017 cancer patients and correlation with anxiety, depression, and distress. Psycho-Oncology. 2019; 28: 2382-2388.

27. Prado-Olivares J, Chover-Sierra E. Preoperatory anxiety in patients undergoing cardiac surgery. Diseases. 2019; 7(2): 46.

28. Vaccarino V, Badimon L, Bremner JD, Cenko E, Cubedo J, Dorobantu M. Depression and coronary heart disease: 2018 position paper of the ESC working group on coronary pathophysiology and microcirculation. Eur Heart J. 2019; 0: 1-15.

29. Kozela M, Bobak M, Beala AM, Micek A, Kubinova R, Malyutina S, et al. The association of depressive symptoms with cardiovascular and all-cause mortality in Central and Extern Europe: Prospective results of the HAPIEE study. Eur J Prev Kardiol. 2016; 23: 1839-1847. 
30. Ansari I, Fallahi F, Ghanem A, Babakhani E, Hashemi Z, Mohammadian $\mathrm{E}$, et al. The relation between depression and ischemic heart disease among middle aged people: a case control study. J Basic Clin Pathophysiol. 2019; 7: 15-20.

31. Cohen BE, Panguluri P, Na B, Whooley MA. Psychological risk factors and the metabolic syndrome in patients with coronary heart disease: findings from the Heart and Soul Study. Psychiatry Res. 2010; 175: $133-7$.

32. Baune BT, Neuhauser H, Ellert U, Berger K. The role of the inflammatory markers ferritin, transferring and fibrinogen in the relationship between major depression and cardiovascular disorders: the German Healt Interview and Examination Survey. Acta Psychiatr Scand. 2010; 121: $135-2$.

33. Chuvet-Gelinier J-C, Bonin B. Stress, anxiety and depression in heart disease patients: A major challenge for cardiac rehabilitation. Ann Physic Rehabil Med. 2017; 60: 6-12.

34. Moser DK, Dracup K, McKinley S, Yamasaki K, Kim CJ, Riegel B. An international perspective on gender differences in anxiety early after acute myocardial infarction. Psychosom Med. 2003; 65: 511-6.

35. Eaker ED, Pinsky J, Castelli WP. Myocardial infarction and coronary death among women: psychosocial predictors from a 20-year follow-up of women in the Framingham Study. Am J Epidemiol. 1992; 135: 854-4.

36. Stone SV, Costa PT. Disease-prone personality or distress-prone personality? The role of neuroticism in coronary heart disease. In: Friedman HS (Ed.). Personality and disease. New York: Wiley, 1990; $178-9$.

37. Eichstaedt JC, Schwartz HA, Kern MI, Park G, Labarthe DR, Merchant RM, et al. Psychological language on Twitter predicts county-level heart rate mortality. Psychol Sci. 2015; 26: 159-9.
38. Alams A, Moller J, Iqbal R, Forsell Y. Effect of neuroticism on risk cardiovascular disease in depressed persons - a Swedish population based cohort study. BMC Cardiovasc Disord. 2017; 17: 185.

39. Costa PT, Zonderman AB, Engel BT, Baile WF, Brimlow DL, Brinker J. The relation of chest pain symptoms to angiographic findings of coronary artery stenosis and neuroticism. Psychosom Med. 1985; 47: 285-3.

40. Costa PT Jr. Influence of the normal personality dimension of neuroticism on chest pain symptoms and coronary artery disease. Am J Cardiol. 1987; 60: 20J-6J.

41. Goldberg LR. An alternative "descriprion of personality": the big-five factor structure. J Pers Soc Psychol. 1990; 59: 1216-9.

42. Luchetti M, Barkley JM, Stephan Y, Terracciano A, Sutin AR. Fivefactor model personality traits and inflammatory markers: new data and meta-analysis. Psychoneuroendocrinology. 2014; 50: 181-3.

43. Mõtus R, Luciano M, Starr JM, Pollard MC, Deary IJ. Personality traits and inflammation in men and women in their early 70s: the Lothian Birth Cohort 1936 study of healthy aging. Psychosom Med. 2013; 75: 11-9.

44. Garcia M, Mulvagh SL, Bairey Merz CN, Bering JE, Manson JE. Cardiovascular disease in women: Clinical perspectives. Circ Res. 2016; 118(8): 1273-1293.

45. Pierce GL, Kalil1 GZ, Ajibewa1 T, Holwerda SW, Persons J, Moser DJ, Fiedorowicz JG. Anxiety independently contributes to elevated inflammation in humans with obesity. Obesity. 2017; 25: 286-289.

46. Simon GE, Von Korff M, Saunders K, Miglioretti DL, Crane PK, van Belle G, Kessler RC. Association between obesity and psychiatric disorders in the US adult population. Arch Gen Psychiatry. 2006; 63(7): 824-830. 